Article

\title{
Trust Repair after Opportunistic Behaviors in the Chinese Construction Projects
}

\author{
Xiaodan Zheng ${ }^{1}$, Shuibo Zhang ${ }^{2, *}$ and Conghan Wang ${ }^{2}$ \\ 1 Department of Construction Management, College of Civil Engineering, Nanjing Forestry University, \\ Nanjing 210037, China; zhengxiaodan90@163.com \\ 2 College of Management and Economics, Tianjin University, Tianjin 300072, China; wangconghan@tju.edu.cn \\ * Correspondence: zhangshuibo@tju.edu.cn
}

Received: 31 May 2018; Accepted: 4 July 2018; Published: 5 July 2018

check for updates

\begin{abstract}
Developing the trust of contractors is important for subcontractors since the trust can help subcontractors obtain a sound reputation and more chances of subcontracting. Nonetheless, the trust can be broken by opportunistic behaviors. Thus, subcontractors should utilize effective trust repair strategies to repair trust after it is violated, so as to maintain the role of trust. As a result, this study compares denial, apology, and penance as strategies for trust repair, after subcontractors demonstrate opportunistic behaviors to violate contractors' trust in construction projects. And this study also discusses the effect of the frequency of opportunistic behaviors on the three trust repair strategies in construction projects. Scenario-based experiments are utilized as a research methodology. According to the experimental results, when a subcontractor demonstrates a single opportunistic behavior to break a contractor's trust, the most effective strategy to repair trust is penance. The least effective strategy is denial. However, when a subcontractor has repeated opportunistic behaviors to break contractor's trust, denial, apology, or penance has only a very limited effectiveness in trust repair. In addition, the effectiveness of the three trust repair strategies does not have significant differences. This study benefits the development of a trust repair theory applicable to construction projects. Moreover, this study offers information to assist subcontractors in utilizing the most efficient strategy to repair the trust that has been violated by opportunistic behaviors in Chinese subcontractors.
\end{abstract}

Keywords: apology; denial; penance; opportunistic behaviors; trust repair; subcontracting; scenariobased experiments

\section{Introduction}

In the construction industry, construction companies play important roles. Construction companies include contractors and subcontractors. Generally, contractors are large-scale construction companies with strong comprehensive strength, whereas subcontractors are small-scale construction companies [1]. However, subcontractors usually have some specialties, such as some technological specialties and labor specialties [1]. Because of weaker comprehensive strength, subcontractors do not have enough capacities to compete with contractors for general contracting jobs. However, subcontractors can rely on their specialties to get subcontracting jobs from contractors [2]. As a result, subcontractors need to depend on contractors to provide subcontracting to maintain existence and development [3]. Thus, building contractors' trust is important for subcontractors. This trust can help subcontractors to earn a good reputation and have more subcontracting opportunities $[4,5]$.

However, trust is vulnerable and fragile [6-8]. In construction projects, subcontractors' opportunistic behaviors (e.g., reduce normal material usage or use unqualified materials) can break contractors' trust in subcontractors and lead to the trust crisis [4,9]. Moreover, these opportunistic behaviors frequently occur in practice [4]. If subcontractors demonstrate opportunistic behaviors to 
break the trust, subcontractors may lose cooperative relationships with contractors $[9,10]$. This may result in subcontractors being dismissed [11]. Moreover, subcontractors who have opportunistic behaviors may lose their reputation. This may result in negative effects in terms of subcontractors' future development [12]. Thus, if subcontractors have opportunistic behaviors to break contractors' trust, it is important and necessary for subcontractors to repair this trust in an effective manner.

Although many studies have discussed trust-building in the construction projects [4,13-15], few studies explore trust repair in the construction projects. Actually, trust repair is different than trust building. Trust repair is more difficult than trust-building because trust repair involves both establishing positive expectations and overcoming negative expectations from opportunistic behaviors [6,16]. Therefore, this study is aimed to help subcontractors to repair trust to deal with the trust crisis, after subcontractors have opportunistic behaviors to break contractors' trust in the Chinese construction projects.

To achieve the research goal, this study reviews the related literature. This is followed by building hypotheses, introducing research methodology, and presenting results. Finally, this study has the discussion and conclusion.

\section{Literature Review}

\subsection{Trust Repair}

Trust is "a psychological state comprising the intention to accept vulnerability based upon positive expectations of the intentions or behavior of another" [8].

Trust is a dynamic process and includes multiple stages. Fulmer and Gelfand [17] showed that trust included a minimum of three stages: formation, dissolution, and restoration. Trust formation is when the trustor chooses to trust the trustee and the trust level increases with time. Trust dissolution is when the trustor decreases the trust level in the trustee after the trustee violates trust. Trust restoration is when the trust level stops decreasing, starts to improve, and then reaches relative stabilization after trust violation. However, trust restoration cannot happen automatically. The trustee needs to adopt trust repair strategies to rebuild positive expectations from the trustor about the trustee [16].

In the field of social psychology, organizational behavior, and marketing, many studies have discussed trust repair strategies. An apology is a common trust repair strategy. An apology refers to a statement that acknowledges both responsibility and regret for a trust violation and promises having good behaviors in the future, so as to provide a credible signal [18]. A denial is also a common trust repair strategy. But a denial is in contrast to an apology. A denial refers to a statement whereby an allegation is explicitly declared to be untrue, and an explanation to demonstrate that mistakes happen unintentionally rather than intentionally, in order to disengage the self from the event [18]. Kim et al. [18] found that a denial was more effective in response to opportunistic behaviors than an apology. However, Han and Ning [19] had a different finding from Kim et al. [18]. Han and Ning [19] found that an apology was more effective than a denial for trust repair after opportunistic behaviors were demonstrated.

Penance is also a common trust repair strategy. An apology and a denial are both verbal strategies, but penance is a substantive strategy. Ren and Gray [20] argued that the sincerity of any verbal strategies was difficult to discern, and penance may be necessary for trust repair, especially when the damaged party had suffered severe consequences. Penance is to pay a price to provide a credible signal for renewed trustworthiness [6]. Penance can be in the form of correction and having good behaviors in the future [21].

In addition, the effectiveness of trust repair strategies can be impacted by trust violation natures [21,22]. Additionally, the frequency of trust violation is important and can influence trust repair. Gunderson and Ferrari [23] and Ferguson and Peterson [24] found that more frequent transgressions resulted in more difficulty in forgiveness and trust repair from recipients. 


\subsection{Development and Destruction of Trust in Construction Projects}

Cerić [25] built a dynamic model of trust among construction project parties. At the beginning of a construction project, trust was usually positive (above zero). As the project proceeded, trust gradually increased as project parties become better acquainted. However, if negative events occurred, these negative events could break trust, precipitously decreasing trust. Thus, trust violators were needed to re-establish trust for returning to a trustful relationship. The progress of rebuilding trust is likely to be slower than the progress of developing trust at the beginning.

Some studies find some factors to positively influence trust in the construction projects. For example, Wong et al. [26] found that competent performance and effective communication could initiate trust in construction projects. Maurer [14] found that a stable pool of project team members and objective project reward criteria facilitated the formation of trust in the construction projects. Chow et al. [27] found that networking and being calculating related positively to trust in the construction projects. Laan et al. [28] found that positive work history and more future prospects were beneficial to developing trust in the construction projects. Lu and Hao [29] found that the expert power of contracting parties had positive effects on building trust in the construction projects. Jiang et al. [30] found that better reputation, more integrity, and more reciprocity could lead to more trust in the construction projects.

On the other hand, some studies also found some factors to have negative effects on trust in the construction projects. For example, Kadefors [31] found that contractual incentives and close monitoring might induce opportunism and start vicious circles of trust in the construction projects. Lu et al. [9] found that external uncertainty could induce opportunism, and opportunism negatively affected trust in the construction projects. Manu et al. [4] found that subcontractors' opportunistic behaviors and poor performance could negatively impact contractors' trust in subcontractors. Wu et al. [32] found that conflicts had negative effects on trust in the construction projects.

\subsection{Problem Statement}

According to the literature review, studies about trust in the construction projects have discussed factors that can positively facilitate trust and factors that negatively influence trust. Opportunism is found as a main factor to break trust in construction projects. However, these studies did not discuss how to repair trust after trust is damaged by opportunistic behaviors in the construction projects.

In the field of social psychology, organizational behavior, and marketing, studies have compared denial, apology, and penance for trust repair, and discussed the effect of trust violation frequency. However, these studies have inconsistent findings. As well, these studies are not based on construction projects. Different research situations can influence research results to a great extent [33]. Thus, these studies do not necessarily help subcontractors to understand how to repair contractors' trust after subcontractors demonstrate opportunistic behaviors to break trust.

Therefore, it is still necessary and important to discuss trust repair in the construction industry. This study aims to compare denial, apology, and penance for trust repair, after subcontractors have demonstrated opportunistic behaviors in construction projects to violate contractors' trust. Moreover, this study also intends to discuss the effect of the frequency of opportunistic behaviors on the three trust repair strategies in construction projects. In addition, culture can influence trust [34]. Thus, this study focuses on Chinese construction projects.

\section{Hypotheses}

\subsection{Denial, Apology, and Penance}

When a contractor finds a subcontractor demonstrates a single opportunistic behavior, the contractor may consider the subcontractor as untrustworthy [1,4]. This is because people are sensitive to negative information about integrity and morality. People think reliable persons do not have opportunistic behaviors in any situation [35]. Thus, even if a person only has a single 
opportunistic behavior, this person may be considered unreliable [36]. Moreover, in construction projects, different contracting parties may pursue different interests. It may result in the tendency for some contracting parties to suspect other contracting parties of harboring malicious intentions [26]. As a result, even though the subcontractor denies the opportunistic behavior and explains that the mistake happens unintentionally, rather than intentionally, the contractor is still less likely to believe in the subcontractor's denial. The contractor may tend to consider that the subcontractor uses denial to cover up opportunistic behavior and remove the responsibility for an offence [21,37]. Besides, a denial has a high possibility of resulting in the contractor considering the subcontractor as impenitent $[19,38]$. Therefore, in construction projects, after a subcontractor demonstrates a single opportunistic behavior to break trust, a denial may be difficult to repair trust. On the contrary, a denial may have the negative effect on trust repair.

Although only one single opportunistic behavior can break trust, it is still possible for the subcontractor to repair the contractor's trust, because it is an isolated incident [23,24]. For the subcontractor, penance may be necessary for trust repair after demonstrating the opportunistic behavior [20]. Penance means correcting the opportunistic behavior and presenting good behaviors in the future [21]. Penance is a substantive action for repentance. Thus, penance is more convincing [6]. After one opportunistic behavior occurs, if the subcontractor can positively correct and maintain honesty, the negative impression that the subcontractor is opportunistic may abate, and the positive impressions that the subcontractor is honest may be reinforced as time goes on [39]. It is beneficial to make the contractor consider the isolated opportunistic behavior as low consistency [40]. It is also beneficial to make the contractor consider that the subcontractor has changed moral traits into honesty and integrity. Thus, the contractor may expect the risk that the subcontractor has opportunistic behaviors again is low. Hence, the contractor may have trust in the subcontractor again [41].

An apology means that the subcontractor acknowledges both responsibility and regret for the opportunistic behavior, and promises to demonstrate good behaviors in the future [18]. An apology can illustrate the willingness of a subcontractor to have a positive correction $[18,20]$, and can relieve the contractor's anger due to the opportunistic behavior [42-44]. However, the opportunistic behavior results in a significant decrease in the reliability of the subcontractor [45]. Thus, the subcontractor cannot prove the apology is sincere, and cannot prove the promise will be fulfilled [39]. Moreover, compared with penance, an apology is a verbal response rather than a substantive action. However, in construction projects, contracting parties always pay more attention to substantive actions rather than verbal responses $[4,46,47]$. Therefore, in a construction project, after a subcontractor demonstrates a single opportunistic behavior to break trust, an apology has lower effectiveness in trust repair than penance, but has higher effectiveness in trust repair than a denial.

Hypothesis 1. In a construction project, after a subcontractor has a single opportunistic behavior to break contractor's trust, penance has higher effectiveness in trust repair than apology and denial; and an apology has higher effectiveness in trust repair than a denial. Figure 1 presents the prediction for Hypothesis 1.

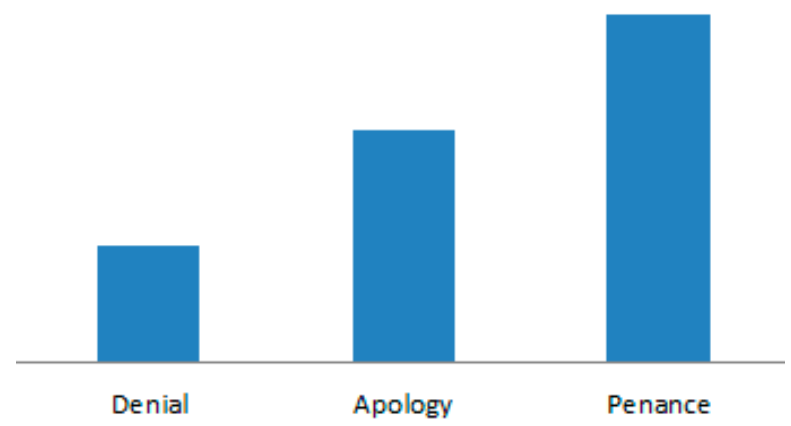

Figure 1. Hypothesis 1: Predicted effectiveness of three trust repair strategies after a subcontractor demonstrates a single opportunistic behavior to break trust. 


\subsection{The Effect of Repeated Opportunistic Behaviors}

According to the above analysis, after a subcontractor shows a single opportunistic behavior, a contractor may consider the subcontractor as untrustworthy $[1,4]$. If a subcontractor has repeated opportunistic behaviors, a contractor can believe with confirmation that the subcontractor is a stable and unchangeable opportunist [48]. According to the attribution theory, if people consider the reason of a thing is stable and unchangeable, people will expect that this thing will occur again in the future [49]. Furthermore, Reeder and Brewer [36] argued that, even if a person who was opportunist had honest behaviors, this person still could not be considered as reliable. This was because this person may have to behave honestly due to the external pressure. However, this person may have opportunistic behaviors again in the context of lax regulation. Thus, if a subcontractor shows repeated opportunistic behaviors, a contractor can expect with high possibility that the subcontractor will continue opportunistic behaviors in the future. Hence, it is less possible for the contractor to trust the subcontractor again [41]. Moreover, after the contractor has suffered repeated opportunistic behaviors, the contractor learns self-protection and is unwilling to trust the subcontractor again [24,50]. Therefore, after a subcontractor has repeated opportunistic behaviors to break trust, it is very difficult for the subcontractor to repair trust. As a result, denial, apology, or penance has little effectiveness in trust repair. In other words, denial, apology, and penance do not significantly differ in effectiveness for trust repair.

Hypothesis 2. In a construction project, after a subcontractor demonstrates repeated opportunistic behaviors to break contractor's trust, denial, apology, and penance do not significantly differ in effectiveness for trust repair.

Hypothesis 3. In a construction project, the frequency of opportunistic behaviors has influence on the effectiveness of trust repair strategies.

Figure 2 presents the prediction for Hypothesis 2.

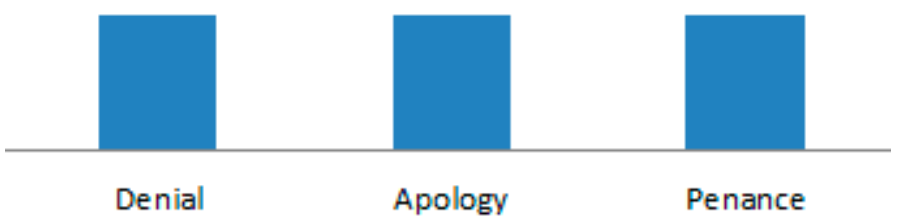

Figure 2. Hypothesis 2: Predicted effectiveness of three trust repair strategies after a subcontractor has repeated opportunistic behaviors to break trust.

\section{Methodology}

This study used scenario-based experiments as the research method. This was because experiments could manipulate different trust repair strategies to observe the change in the trust level [33]. The scenario-based experiment method has been widely used in the studies about trust repair $[6,16,41]$.

Research participants were asked to read a scenario in which a subcontractor has a single opportunistic behavior or repeated opportunistic behaviors in a construction project, and then repairs trust with apology, denial, or penance. After viewing the scenario, participants were asked to report their trust in the subcontractor. Thus, this study used a 2 (frequency: a single opportunistic behavior vs. repeated opportunistic behaviors) $\times 3$ (trust repair strategy: denial vs. apology vs. penance) between-subject design.

\subsection{Experimental Procedure}

All participants came to a big classroom. Before starting the experiment, all participants were randomly assigned to one of the six scenarios. In this way, potential impacts caused by personal 
characteristics of participants could be ruled out [33]. Then experimenters explained the experimental procedure for participants. After that, the experiment began. All participants sat in a classroom, but each participant finished the experiment independently. There was no communication or discussion among participants. The experimental process was supervised. During the experimental process, experimenters could immediately answer any questions about the experimental procedure, but experimenters did not give any hints about the experimental result to participants.

The experiment was conducted following the 6 main steps showed in Figure 3.

Step 1: Each participant read the first half of a scenario about a subcontractor in a construction project who presented a single opportunistic behavior or had repeated opportunistic behaviors.

Step 2: Each participant answered one question about the first half of the scenario.

Step 3: Each participant assessed the trust in the subcontractor.

Step 4: Each participant then read the second half of the scenario, where the subcontractor offered apology, denial, or penance as the response.

Step 5: Each participant answered one question about the second half of the scenario.

Step 6: Each participant assessed the trust in the subcontractor again.

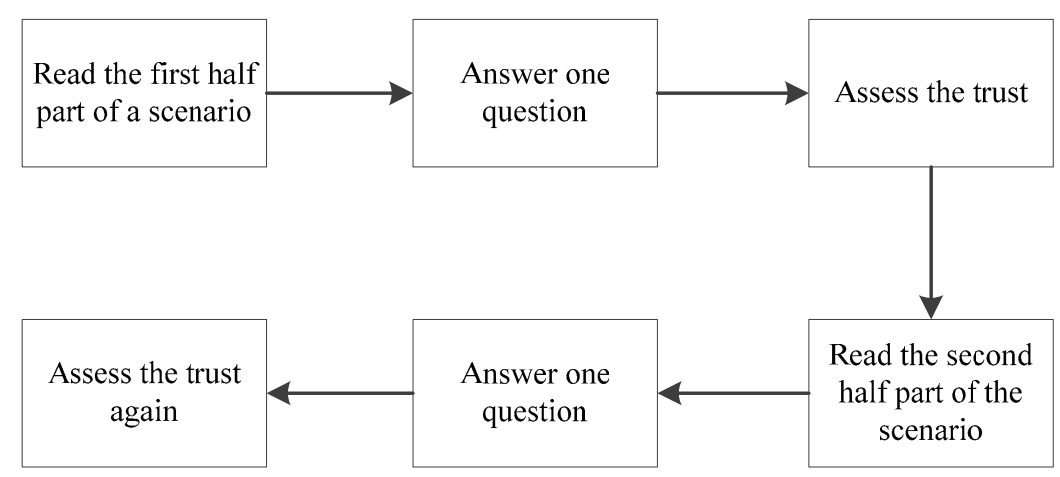

Figure 3. The experimental procedure.

\subsection{Participants}

This study discussed trust repair strategies, in order to help subcontractors repair contractors' trust in subcontractors. Thus, contractors were needed to evaluate the effectiveness of trust repair strategies.

One-hundred-and-two participants were contractors from China. They participated in a project management workshop. Thus, they were invited to participate in this study.

\subsection{Manipulations}

\subsubsection{Trust Violation}

The first half part of a scenario was that in a construction project, a subcontractor had a single opportunistic behavior or had repeated opportunistic behaviors to break the contractor's trust. The first half part of a scenario was designed according to Manu et al. [4].

In a single opportunistic behavior condition, a contractor found that a subcontractor reduced normal material usage, so as to harm the quality. However, it was the first time that this contractor found this subcontractor reduced normal material usage in the construction project.

In repeated opportunistic behaviors condition, a contractor found that a subcontractor reduced normal material usage, so as to harm the quality. Moreover, this contractor found this subcontractor repeatedly reduced normal material usage in the construction project. 


\subsubsection{Trust Repair}

The second half part of a scenario was that the subcontractor took one trust repair strategy (denial, apology, or penance) for trust repair.

In the denial condition, the subcontractor denied intentionally reducing normal material usage. Additionally, the subcontractor explained that it was because new workers were not familiar with drawings and specifications so as to unintentionally reduce material usage.

In the apology condition, the subcontractor apologized for reducing normal material usage, and promised not to make similar mistakes in the subsequent work.

In the penance condition, the subcontractor corrected to fulfill the quality requirement. After correction, the subcontractor kept honest in the subsequent work.

\subsection{Checks}

In the experiment, after participants read the first half part of a scenario, participants needed to answer one check question. This question was designed to assess whether participants understood the first half part of a scenario [51]. More specifically, participants were asked, "How many times did the subcontractor reduce normal material usage in the construction project?" The available options included "the first time" and "several times."

After participants read the second half part of a scenario, participants also needed to answer one check question. This question was designed to assess whether participants understood the second half part of a scenario [51]. More specifically, participants were asked, "Which behavior did the subcontractor have as a response for reducing normal material usage in the construction project?" The available options were "denial", "apology", and "correction and penance."

\subsection{Assessment of Trust}

To evaluate the effectiveness of trust repair strategies properly, it was necessary to look at the relative increases in trust [52]. More specifically, trust was measured twice. After participants read the first half part of a scenario (only including the trust violation), participants needed to assess trust. After participants read the second half part of a scenario (including the trust violation and trust repair), participants needed to assess trust again.

The relative increases in trust (i.e., the effectiveness of trust repair strategies) $=$ the trust level at the second time- the trust level at the first time.

Trust was measured using two items, according to Pinto et al. [53]. The measurement was based on a seven-point Likert scale, from 1 (strongly disagree) to 7 (strongly agree). The items were: (1) we believe that this subcontractor does not knowingly hurt the contractor in order to benefit themselves; (2) we believe that this subcontractor has high levels of honesty and integrity. The Cronbach's alpha value at the first time was 0.91 , and the Cronbach's alpha value at the second time was 0.94 .

\subsection{Data Analysis}

This study used a 2 (frequency: a single opportunistic behavior vs. repeated opportunistic behaviors) $\times 3$ (trust repair strategy: denial vs. apology vs. penance) between-subject design. Thus, a two-way analysis of variance was suitable for data analysis [54]. SPSS 18 software was used.

\section{Results}

\subsection{Checks}

This study only used the data from the participants who answered all two check questions correctly to test the hypotheses. This was because only data from the participants who fully understood the scenario were valid [55]. The number of valid participants was 90 . 


\subsection{Experimental Results}

According to the two-way analysis of variance (frequency $\times$ trust repair strategy), the frequency of opportunistic behaviors had a significant effect on the effectiveness of trust repair strategies $(\mathrm{F}(1,84)$ $=9.091, p=0.003<0.050$ ). In other words, the effectiveness of trust repair strategies in a single opportunistic behavior condition was significantly different compared with the effectiveness of trust repair strategies in the repeated opportunistic behaviors condition. In addition, the interaction effect between the frequency of opportunistic behaviors and trust repair strategies was also significant $(\mathrm{F}(2,84)=3.671, p=0.030<0.050)$, showed in Figure 4. Therefore, Hypothesis 3 was supported. In a construction project, the frequency of opportunistic behaviors could influence the effectiveness of trust repair strategies.

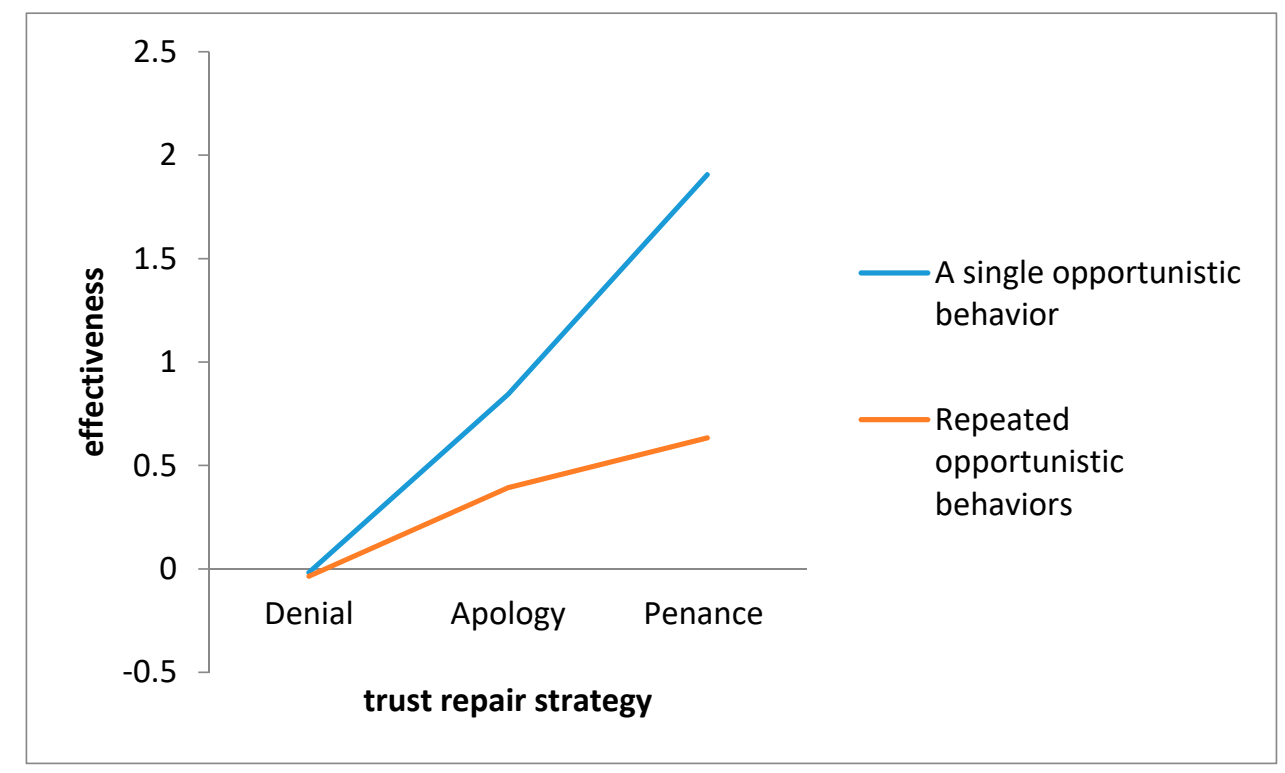

Figure 4. The interaction effect between the frequency of opportunistic behaviors and trust repair strategies.

When the interaction effect is significant, it is necessary to test the individual main effect [54]. All the data were segmented according to the frequency of opportunistic behaviors. A one-way analysis of variance was used to test the individual main effect [54].

In the single opportunistic behavior condition, different trust repair strategies had significantly different effectiveness in trust repair $(\mathrm{F}(2,44)=13.514, p=0.000<0.050)$. Specifically, in Tables 1 and 2, penance was the most effective in increasing trust level $(\mathrm{M}=1.906, \mathrm{SD}=1.217)$, and its effectiveness was significantly better than the effectiveness of the denial (1.906 vs. -0.017 ; mean difference $=1.923$, $p=0.000<0.050)$, and the effectiveness of the apology $(1.906$ vs. 0.844 ; mean difference $=1.063$, $p=0.006<0.050)$. The effectiveness of the apology ranked second $(\mathrm{M}=0.844, \mathrm{SD}=1.004)$, and its effectiveness was significantly better than the effectiveness of denial ( 0.844 vs. -0.017 ; mean difference $=0.860 ; p=0.025<0.050)$. The effectiveness of denial was the lowest $(\mathrm{M}=-0.017, \mathrm{SD}=0.826)$. Moreover, a denial had a negative effect on increasing trust level. Thus, Hypothesis 1 was supported. In a construction project, after a subcontractor demonstrated a single opportunistic behavior to break a contractor's trust, penance had higher effectiveness in trust repair than apology and denial; and apology had higher effectiveness in trust repair than denial. 
Table 1. Descriptive statistics.

\begin{tabular}{ccccc}
\hline \multirow{2}{*}{ Frequency } & Strategy & N & \multicolumn{2}{c}{ Effectiveness } \\
\cline { 5 - 5 } & & & M & SD \\
\hline \multirow{3}{*}{ A single opportunistic behavior } & Denial & 15 & -0.017 & 0.826 \\
& Apology & 16 & 0.844 & 1.004 \\
& Penance & 16 & 1.906 & 1.217 \\
\hline \multirow{2}{*}{ Repeated opportunistic behaviors } & Denial & 14 & -0.036 & 0.603 \\
& Apology & 14 & 0.393 & 1.059 \\
& Penance & 15 & 0.633 & 0.516 \\
\hline
\end{tabular}

Table 2. Multiple comparisons.

\begin{tabular}{|c|c|c|c|c|}
\hline \multirow{2}{*}{ Frequency } & \multirow{2}{*}{$\begin{array}{c}\text { (I) } \\
\text { Strategy }\end{array}$} & \multirow{2}{*}{$\begin{array}{c}(\mathrm{J}) \\
\text { Strategy }\end{array}$} & \multicolumn{2}{|c|}{ Effectiveness } \\
\hline & & & $(\mathrm{I}-\mathrm{J})$ & $p$ \\
\hline \multirow{6}{*}{ A single opportunistic behavior } & \multirow[t]{2}{*}{ Denial } & Apology & $-0.860 *$ & 0.025 \\
\hline & & Penance & $-1.923 *$ & 0.000 \\
\hline & \multirow{2}{*}{ Apology } & Denial & $0.860 *$ & 0.025 \\
\hline & & Penance & $-1.063 *$ & 0.006 \\
\hline & \multirow[t]{2}{*}{ Penance } & Denial & $1.923 *$ & 0.000 \\
\hline & & Apology & $1.063 *$ & 0.006 \\
\hline \multirow{6}{*}{ Repeated opportunistic behaviors } & \multirow[t]{2}{*}{ Denial } & Apology & -0.429 & 0.338 \\
\hline & & Penance & -0.669 & 0.072 \\
\hline & \multirow{2}{*}{ Apology } & Denial & 0.429 & 0.338 \\
\hline & & Penance & -0.240 & 0.698 \\
\hline & \multirow[t]{2}{*}{ Penance } & Denial & 0.669 & 0.072 \\
\hline & & Apology & 0.240 & 0.698 \\
\hline
\end{tabular}

Note: ${ }^{*} p<0.050$.

However, in a repeated opportunistic behaviors condition, different trust repair strategies did not have significant differences in effectiveness $(\mathrm{F}(2,40)=2.868, p=0.069)$. Thus, Hypothesis 2 was supported. In a construction project, after a subcontractor had repeated opportunistic behaviors to break a contractor's trust, denial, apology, and penance did not significantly differ in effectiveness for trust repair.

\section{Discussion}

\subsection{A Single Opportunistic Behavior}

According to the experimental results, when a subcontractor only has a single opportunistic behavior to break a contractor's trust, the most effective trust repair strategy is penance. The level of trust has the most improvement after the subcontractor uses penance to repair trust. In other words, in a construction project, after a subcontractor has a single opportunistic behavior to break a contractor's trust, penance has higher effectiveness in trust repair than apology and denial. Penance is a substantive trust repair strategy. An apology and a denial are both verbal trust repair strategies. Thus, this finding illustrates that in the construction projects, substantive trust repair strategies have higher effectiveness in trust repair than verbal trust repair strategies. This is because in construction projects, contracting parties always pay more attention to substantive actions rather than verbal responses [4,46,47]. This finding supports Bottom et al. [21] and Ren and Gray [20].

An apology and a denial can be compared further. This study finds that an apology has higher effectiveness in trust repair than a denial, after a subcontractor only demonstrates a single opportunistic behavior to break a contractor's trust. This finding in this study is consistent with that of Han and Ning [19], who found that denials were less effective than apologies for repairing integrity-based trust in China. However, Kim et al. [18] and Ferrin et al. [51] argued that denials were more effective than 
apologies when repairing integrity-based trust. Schweitzer et al. [39] and Desmet et al. [52] found that a trust violation with a bad intent was more difficult to repair than a trust violation without a bad intent. Thus, Kim et al. [18] and Ferrin et al. [51] thought that for repairing integrity-based trust, an apology illustrated a violator acknowledged a bad intent, but a denial illustrated the violator denied the bad intent. In other words, a denial could eliminate the suspicion that the violator had the bad intent $[18,51]$. However, Schlenker et al. [37] argued whether a denial could help repair trust depended on whether the trustor believed the denial. Kim et al. [18] and Ferrin et al. [51] were based on western culture. In western culture, most people are initially considered as trustworthy until dishonest behaviors occur to damage trust [56]. Thus, in Western culture, when a trustor cannot affirm a violator has a bad intent, the trustor may tend to believe the violator's denial. However, in the Chinese culture, most people are not considered trustworthy until they prove that they are trustworthy [56]. Thus, in China, although a trustor cannot affirm a violator has a bad intent, the trustor may tend not to believe the violator's denial. Moreover, in construction projects, interests of different contracting parties are not accordant so that contracting parties tend to suspect other contracting parties [26]. Thus, contractors are more prone not to believe subcontractors' denials. And contractors may think that subcontractors use denials to shirk their responsibilities. Hence, this study found that a denial had a negative influence on trust repair, after a subcontractor had an opportunistic behavior.

\subsection{Repeated Opportunistic Behaviors}

The finding also illustrates that the frequency of the opportunistic behavior has significant effect on the effectiveness of trust repair strategies. After a subcontractor has a single opportunistic behavior to break a contractor's trust, penance is the most effective strategy to repair trust. However, after a subcontractor has repeated opportunistic behaviors to break a contractor's trust, denial, apology, or penance has a very limited effectiveness in trust repair. Therefore, in the construction project, more frequent opportunistic behaviors can result in more difficulties to repair trust. This finding supports the opinion of Gunderson and Ferrari [23] and Ferguson and Peterson [24]. Thus, subcontractors should maintain honesty and avoid demonstrating the opportunistic behavior again after they repair the first trust violation.

\section{Conclusions}

This study compared denial, apology, and penance for trust repair after subcontractors demonstrated opportunistic behaviors to violate contractors' trust in construction projects. This study also discussed the effect of the frequency of opportunistic behaviors on the three trust repair strategies in construction projects.

This study found when a subcontractor had a single opportunistic behavior to break a contractor's trust, the most effective strategy to repair trust was penance. The least effective strategy to repair trust was denial. Moreover, denial had a negative influence on trust repair. The level of trust could continue decreasing after subcontractors used denial. However, when a subcontractor demonstrated repeated opportunistic behaviors to break contractor's trust, denial, apology, or penance only had a very limited effectiveness in trust repair. In addition, the effectiveness of the three trust repair strategies did not have significant differences.

In construction project management, existing literature lacks analyses of trust repair. This study can fill the research gap in existing literature and develops trust repair theory in construction project management. Furthermore, this study provides decision supports and theoretical guidance to subcontractors for repairing contractors' trust. In addition, this study helps subcontractors deal with trust violations caused by opportunistic behaviors, and helps subcontractors continue to sustain trust of contractors. In addition, this study also discussed the differences between western culture and Chinese culture on trust repair. Thus, this study can also help global construction companies who want to enter the Chinese construction market to better understand the culture of repairing and maintaining trust with Chinese construction companies. 
There are some limitations in this study, and hence, recommendations for future research. Firstly, this study focuses on Chinese construction projects. All participants in the experiments are Chinese contractors. However, trust may be influenced by culture. Thus, for future research, it is interesting to investigate the effectiveness of trust repair strategies in global construction projects. Secondly, this study only discusses the influence of the frequency of opportunistic behaviors on trust repair. However, other factors, such as characteristics of construction projects and prior cooperation experience, may also impact trust repair. Thus, future studies can continue to discuss influences of more factors on the effectiveness of trust repair strategies. Finally, this study focuses on subcontractors repairing contractors' trust. This is because in relationships between contractors and subcontractors in China, contractors are more powerful and subcontractors are more dependent on contractors. However, future studies can explore trust repair after other contracting parties violate the trust.

Author Contributions: X.Z. conceived and designed the experiments; C.W. and S.Z. performed the experiments; S.Z. provided the funding; X.Z. analyzed the data and wrote the paper.

Funding: National Natural Science Foundation of China (Grants 71572124).

Acknowledgments: The authors thank the National Natural Science Foundation of China for financial support (Grants 71572124); thank Xinyi Song's and Jingfeng Yuan's suggestions; and thank all participants in the experiments.

Conflicts of Interest: The authors declare no conflict of interest.

\section{References}

1. Yik, F.W.; Lai, J.H.; Chan, K.T.; Yiu, E.C.; Yik, F.W.; Lai, J.H.; Chan, K.T.; Yiu, E.C. Problems with specialist subcontracting in the construction industry. Build. Serv. Eng. Res. Technol. 2006, 27, 183-193. [CrossRef]

2. Arditi, D.; Chotibhongs, R. Issues in Subcontracting Practice. J. Constr. Eng. Manag. 2005, 131, 866-876. [CrossRef]

3. Manu, P.; Ankrah, N.; Proverbs, D.; Suresh, S. Mitigating the health and safety influence of subcontracting in construction: The approach of main contractors. Int. J. Proj. Manag. 2013, 31, 1017-1026. [CrossRef]

4. Manu, E.; Ankrah, N.; Chinyio, E.; Proverbs, D. Trust influencing factors in main contractor and subcontractor relationships during projects. Int. J. Proj. Manag. 2015, 33, 1495-1508. [CrossRef]

5. Swift, T. Trust, reputation and corporate accountability to stakeholders. Bus. Ethics A Eur. Rev. 2001, 10, 16-26. [CrossRef]

6. Dirks, K.T.; Kim, P.H.; Ferrin, D.L.; Cooper, C.D. Understanding the effects of substantive responses on trust following a transgression. Organ. Behav. Hum. Decis. Process. 2011, 114, 87-103. [CrossRef]

7. Mayer, R.C.; Davis, J.H.; Schoorman, F.D. An Integrative Model of Organizational Trust. Acad. Manag. Rev. 1995, 20, 709-734. [CrossRef]

8. Rousseau, D.M.; Sitkin, S.B.; Burt, R.S.; Camerer, C. Not so Different after All: A Cross-Discipline View of Trust. Acad. Manag. Rev. 1998, 23, 393-404. [CrossRef]

9. Lu, P.; Qian, L.; Chu, Z.; Xu, X. Role of Opportunism and Trust in Construction Projects: Empirical Evidence from China. J. Manag. Eng. 2015, 32, 05015007. [CrossRef]

10. Malhotra, D.; Lumineau, F. Trust and collaboration in the aftermath of conflict: The effects of contract structure. Acad. Manag. J. 2011, 54, 981-998. [CrossRef]

11. Faems, D.; Janssens, M.; Madhok, A.; Looy, B.V. Toward an Integrative Perspective on Alliance Governance: Connecting Contract Design, Trust Dynamics, and Contract Application. Acad. Manag. J. 2008, 51, 1053-1078. [CrossRef]

12. Coombs, W.T.; Holladay, S.J. Communication and Attributions in a Crisis: An Experimental Study in Crisis Communication. J. Public Relat. Res. 1996, 8, 279-295. [CrossRef]

13. Lui, S.S.; Ngo, H.Y.; Hon, A.H.Y. Coercive strategy in interfirm cooperation: Mediating roles of interpersonal and interorganizational trust. J. Bus. Res. 2006, 59, 466-474. [CrossRef]

14. Maurer, I. How to build trust in inter-organizational projects: The impact of project staffing and project rewards on the formation of trust, knowledge acquisition and product innovation. Int. J. Proj. Manag. 2010, 28, 629-637. [CrossRef] 
15. Laan, A.; Noorderhaven, N.; Voordijk, H.; Dewulf, G. Building trust in construction partnering projects: An exploratory case-study. J. Purch. Supply Manag. 2011, 17, 98-108. [CrossRef]

16. Kim, P.H.; Dirks, K.T.; Cooper, C.D.; Ferrin, D.L. When more blame is better than less: The implications of internal vs. external attributions for the repair of trust after a competence vs. integrity-based trust violation. Organ. Behav. Hum. Decis. Process. 2006, 99, 49-65. [CrossRef]

17. Fulmer, A.; Gelfand, M.J. Dynamic trust processes: Trust dissolution and restoration. In Proceedings of the 23rd Annual International Association for Conflict Management Conference, Boston, MA, USA, 24-27 July 2010.

18. Kim, P.H.; Ferrin, D.L.; Cooper, C.D.; Dirks, K.T. Removing the Shadow of Suspicion: The Effects of Apology versus Denial for Repairing Competence versus Integrity-Based Trust Violations. J. Appl. Psychol. 2004, 89, 104-118. [CrossRef] [PubMed]

19. Han, P.; Ning, J. Trust repair strategy based on two types of trust violation. Chin. J. Manag. 2013, 10, 390-396. (In Chinese)

20. Ren, H.; Gray, B. Repairing Relationship Conflict: How Violation Types and Culture Influence the Effectiveness of Restoration Rituals. Acad. Manag. Rev. 2009, 34, 105-126. [CrossRef]

21. Bottom, W.P.; Gibson, K.; Daniels, S.E.; Murnighan, J.K. When Talk Is Not Cheap: Substantive Penance and Expressions of Intent in Rebuilding Cooperation. Organ. Sci. 2002, 13, 497-513. [CrossRef]

22. Lewicki, R.J.; Brinsfield, C. Trust Repair. Annu. Rev. Org. Psychol. Organ. Behav. 2017, 4, 287-313. [CrossRef]

23. Gunderson, P.R.; Ferrari, J.R. Forgiveness of sexual cheating in romantic relationships: Effects of discovery method, frequency of offense, and presence of apology. N. Am. J. Psychol. 2008, 10, 1-14.

24. Ferguson, A.J.; Peterson, R.S. Sinking slowly: Diversity in propensity to trust predicts downward trust spirals in small groups. J. Appl. Psychol. 2015, 100, 1012-1024. [CrossRef] [PubMed]

25. Cerić, A. Trust in Construction Projects; Routledge: Abingdon, UK, 2016.

26. Wong, P.S.P.; Cheung, S.O.; Ho, P.K.M. Contractor as Trust Initiator in Construction Partnering-Prisoner's Dilemma Perspective. J. Constr. Eng. Manag. 2005, 131, 1045-1053. [CrossRef]

27. Chow, P.T.; Cheung, S.O.; Chan, K.Y. Trust-building in construction contracting: Mechanism and expectation. Int. J. Proj. Manag. 2012, 30, 927-937. [CrossRef]

28. Laan, A.; Voordijk, H.; Noorderhaven, N.; Dewulf, G. Levels of Interorganizational Trust in Construction Projects: Empirical Evidence. J. Constr. Eng. Manag. 2012, 138, 821-831. [CrossRef]

29. Lu, S.; Hao, G. The influence of owner power in fostering contractor cooperation: Evidence from China. Int. J. Proj. Manag. 2013, 31, 522-531. [CrossRef]

30. Jiang, W.; Lu, Y.; Le, Y. Trust and Project Success: A Twofold Perspective between Owners and Contractors. J. Manag. Eng. 2016, 32, 04016022. [CrossRef]

31. Kadefors, A. Trust in project relationships-Inside the black box. Int. J. Proj. Manag. 2004, 22, $175-182$. [CrossRef]

32. Wu, G.; Zhao, X.; Zuo, J. Relationship between Project's Added Value and the Trust-Conflict Interaction among Project Teams. J. Manag. Eng. 2017, 33, 04017011. [CrossRef]

33. Chen, X.P.; Tsui, A.; Farh, J.L. Empirical Methods in Organization and Management Research; Peking University Press: Beijing, China, 2008.

34. Schoorman, F.D.; Mayer, R.C.; Davis, J.H. An integrative model of organizational trust: Past, present, and future. Acad. Manag. Rev. 2007, 32, 344-354. [CrossRef]

35. Nooteboom, B. Forms, Sources and Processes of Trust; Handbook of trust research; Bachmann, R., Zaheer, A., Eds.; Edward Elgar Publishing: Cheltenham, UK, 2006.

36. Reeder, G.D.; Brewer, M.B. A schematic model of dispositional attribution in interpersonal perception. Psychol. Rev. 1979, 86, 61-79. [CrossRef]

37. Schlenker, B.R.; Pontari, B.A.; Christopher, A.N. Excuses and character: Personal and social implications of excuses. Pers. Soc. Psychol. Rev. 2001, 5, 15-32. [CrossRef]

38. Xu, B. Government Trust Damage, Repair Mechanism and Coping Strategies after Public Crisis: Analysis and Empirical Study Based on Attribution Theory. J. Public Adm. 2014, 11, 27-38.

39. Schweitzer, M.E.; Hershey, J.C.; Bradlow, E.T. Promises and lies: Restoring violated trust. Organ. Behav. Hum. Decis. Process. 2006, 101, 1-19. [CrossRef]

40. Kelley, H.H. Attribution theory in social psychology. In Nebraska Symposium on Motivation Lincoln; University of Nebraska Press: Lincoln, NE, USA, 1967. 
41. Nakayachi, K.; Watabe, M. Restoring trustworthiness after adverse events: The signaling effects of voluntary "Hostage Posting" on trust. Organ. Behav. Hum. Decis. Process. 2005, 97, 1-17. [CrossRef]

42. Ohbuchi, K.; Kameda, M.; Agarie, N. Apology as aggression control: Its role in mediating appraisal of and response to harm. J. Pers. Soc. Psychol. 1989, 56, 219-227. [CrossRef] [PubMed]

43. Klackl, J.; Pfundmair, M.; Agroskin, D.; Jonas, E. Who is to blame? Oxytocin promotes nonpersonalistic attributions in response to a trust betrayal. Boil. Psychol. 2013, 92, 387-394. [CrossRef] [PubMed]

44. Trafimow, D.; Bromgard, I.K.; Finlay, K.A.; Ketelaar, T.; Trafimow, D.; Bromgard, I.K.; Finlay, K.A.; Ketelaar, T. The role of affect in determining the attributional weight of immoral behaviors. Pers. Soc. Psychol. Bull. 2005, 31, 935-948. [CrossRef] [PubMed]

45. Harmon, D.J.; Kim, P.H.; Mayer, K.J. Breaking the letter vs. spirit of the law: How the interpretation of contract violations affects trust and the management of relationships. Strat. Manag. J. 2015, 36, 497-517. [CrossRef]

46. Wong, P.S.P.; Cheung, S.O. Trust in construction partnering: Views from parties of the partnering dance. Int. J. Proj. Manag. 2004, 22, 437-446. [CrossRef]

47. Khalfan, M.M.; Mcdermott, P.; Swan, W. Building trust in construction projects. Supply Chain Manag. Int. J. 2007, 12, 385-391. [CrossRef]

48. Tomlinson, E.C.; Mayer, R.C. The Role of Causal Attribution Dimensions in Trust Repair. Acad. Manag. Rev. 2009, 34, 85-104. [CrossRef]

49. Weiner, B.; Nierenberg, R.; Goldstein, M. Social learning (locus of control) versus attributional (causal stability) interpretations of expectancy of success. J. Pers. 1976, 44, 52-68. [CrossRef]

50. Tomlinson, E.C.; Dineen, B.R.; Lewicki, R.J. The Road to Reconciliation: Antecedents of Victim Willingness to Reconcile Following a Broken Promise. J. Manag. 2004, 30, 165-187. [CrossRef]

51. Ferrin, D.L.; Kim, P.H.; Cooper, C.D.; Dirks, K.T.; Ferrin, D.L.; Kim, P.H.; Cooper, C.D.; Dirks, K.T. Silence speaks volumes: The effectiveness of reticence in comparison to apology and denial for responding to integrity- and competence-based trust violations. J. Appl. Psychol. 2007, 92, 893-908. [CrossRef] [PubMed]

52. Desmet, P.T.M.; Cremer, D.D.; Dijk, E.V. In money we trust? The use of financial compensations to repair trust in the aftermath of distributive harm. Organ. Behav. Hum. Decis. Process. 2011, 114, 75-86. [CrossRef]

53. Pinto, J.K.; Slevin, D.P.; English, B. Trust in projects: An empirical assessment of owner/contractor relationships. Int. J. Proj. Manag. 2009, 27, 638-648. [CrossRef]

54. Qiu, H.Z. Quantitative Research and Statistical Analysis: Examples of SPSS (PASW) Data Analysis; Chongqing University Press: Chongqing, China, 2013.

55. Shapiro, D.L. The Effects of Explanations on Negative Reactions to Deceit. Adm. Sci. Q. 1991, 36, 614-630. [CrossRef]

56. De Cremer, D. Understanding trust in China and the West. Harvard Bus. Rev. 2015, 11, 1-4. 